\title{
LUIS DE MORALES Y LEONARDO. NUEVAS FUENTES ICONOGRÁFICAS
}

El nombre del maestro de Vinci era sinónimo en España de «gran artista». La fama de este pintor, conocido en la Península Ibérica ya desde finales del siglo xv, alcanzó su apogeo en la primera mitad del siglo siguiente. Francisco de Holanda, primer historiador de la pintura española y portuguesa, en su tratado «Da Pintura Antigua» (1548), calificándoles de «águilas» del arte contemporáneo italiano, otorgaba el primer puesto a Miguel Ángel, tras el cual «seguía Leonardo da Vinci, descubridor y pionero con su valiente contraposición de luz y sombra» ${ }^{1}$.

Es poco probable que en el siglo xvi hubiese en la península ibérica obras originales del gran artista italiano. Aunque en muchos inventarios de colecciones reales y privadas se enumeraban obras de Leonardo, es un hecho conocido que se trata de obras de sus discípulos o de copias de sus obras originales ${ }^{2}$. Así, por ejemplo, una de las primeras menciones de una copia del cuadro «Virgen y el Niño» realizada por Lorenzo di Credi y enviada a España se puede encontrar en Vasari ${ }^{3}$. Francisco de los Santos ejecutó una copia de la «Ultima Cena» que Felipe II regaló al Escorial como obra original de Leonardo da Vinci ${ }^{4}$. En España había también numerosas réplicas del cuadro «La Virgen del huso», hoy perdido, así como copias de la «Virgen del clavel»y «La Sagrada familia con Santa Ana» ${ }^{5}$.

En colecciones españolas se guardaba un considerable número de los llamados «leonardescos», que están vinculados en parte a la unión del Ducado de Milán a la corona española y al establecimiento del protectorado español en 1535. Pedro Fernández de Velasco, cuarto Condestable de Castilla, duque de Feria y conde de Haro, regaló a la catedral de Burgos el cuadro «Santa María Magdalena» atribuido a Leonardo da Vinci. En el inventario de la Capilla del Condestable de dicha catedral burgalesa la obra aparece mencionada ya en 1548. Esta es una de las primeras obras de la pintura de la escuela lombarda en tierras de Castilla. Hoy en día se atribuye a Giampetrino, discípulo de Leonardo ${ }^{6}$. Felipe II trasladó al Escorial el cuadro de Bernardino Luini «La Sagrada Familia» que también entonces se creía obra de Leonardo ${ }^{7}$. Las investigaciones de los últimos decenios han descubierto en España muchas obras de aquella época pertenecientes a B. Luini, Giampetrino, A. Solario, Cesare da Sesto o Marco d'Oggiono, así como copias de las mismas.

Aunque entre los pintores españoles no aparecen seguidores directos de Leonardo, el influjo del arte del genial florentino se percibe en la obra de los pintores valencianos Fernando de Llanos, Fernando Yañez de la Almedina, Vicente Macip, Joan de Joanes y en el artista extremeño Luis de Morales ${ }^{8}$. Como justamente observaba E. Solovieva al analizar la interacción de la pintura italiana y española en la primera mitad del siglo XVI y dentro de ella la influencia de Leonardo da Vinci, el contacto de los maestros españoles con las obras italianas y el curso mismo de la evolución del arte de aquel tiempo, manifiestan que las formas más cercanas para los artistas españoles fueron las formas manieristas ${ }^{9}$.

\footnotetext{
${ }^{1}$ Francisco de Holanda, Da Pintura Antigua (1548). Cit. por Backsbacka J.: Luis de Morales. Helsinki, 1962, p. 28.

${ }^{2}$ Ruiz Manero, J.M., Pintura italiana del siglo XVI en España. Leonardo y los leonardescos, tomo I. Madrid, 1996, $\mathrm{p}$ 7.

${ }^{3}$ Ibídem.

${ }^{4}$ Trapie Du Gue, E., Luis de Morales and leonardesque influences in Spain. New York, 1953, p.17.

${ }^{5}$ Ruiz Manero, J.M.: Op. cit., p. 15.

${ }^{6}$ Trapie Du Gue, E.: Op. cit., pp. 17, 18, 41.

7 Véase: Felipe II. Un monarca y su época. Un príncipe del renacimiento. Exp. Museo Nacional del Prado. 1998-1999. Madrid, 1999, pp. 488, 489, cat. n. ${ }^{\circ} 147$.

${ }^{8}$ Trapie Du Gue, E.: Op. cit., pp. 1-45; Solovieva, E. I., «K voprosu o vliyanii Leonardo da Vinci na ispanskuyu zhivopis XVI veka», Nauchnaia konferentsiia pamiati M.A. Gukovskogo. Tezisy dokladov. Sankt Peterburg, 1998, pp. 43-44; Ruiz Manero, J.M.: Op. cit., pp. 17-18.

${ }^{9}$ Solovieva, E. I.: Op.cit., p.43.
}

$A E A$, LXXVII, 2004, 308, pp. 411 a 438 

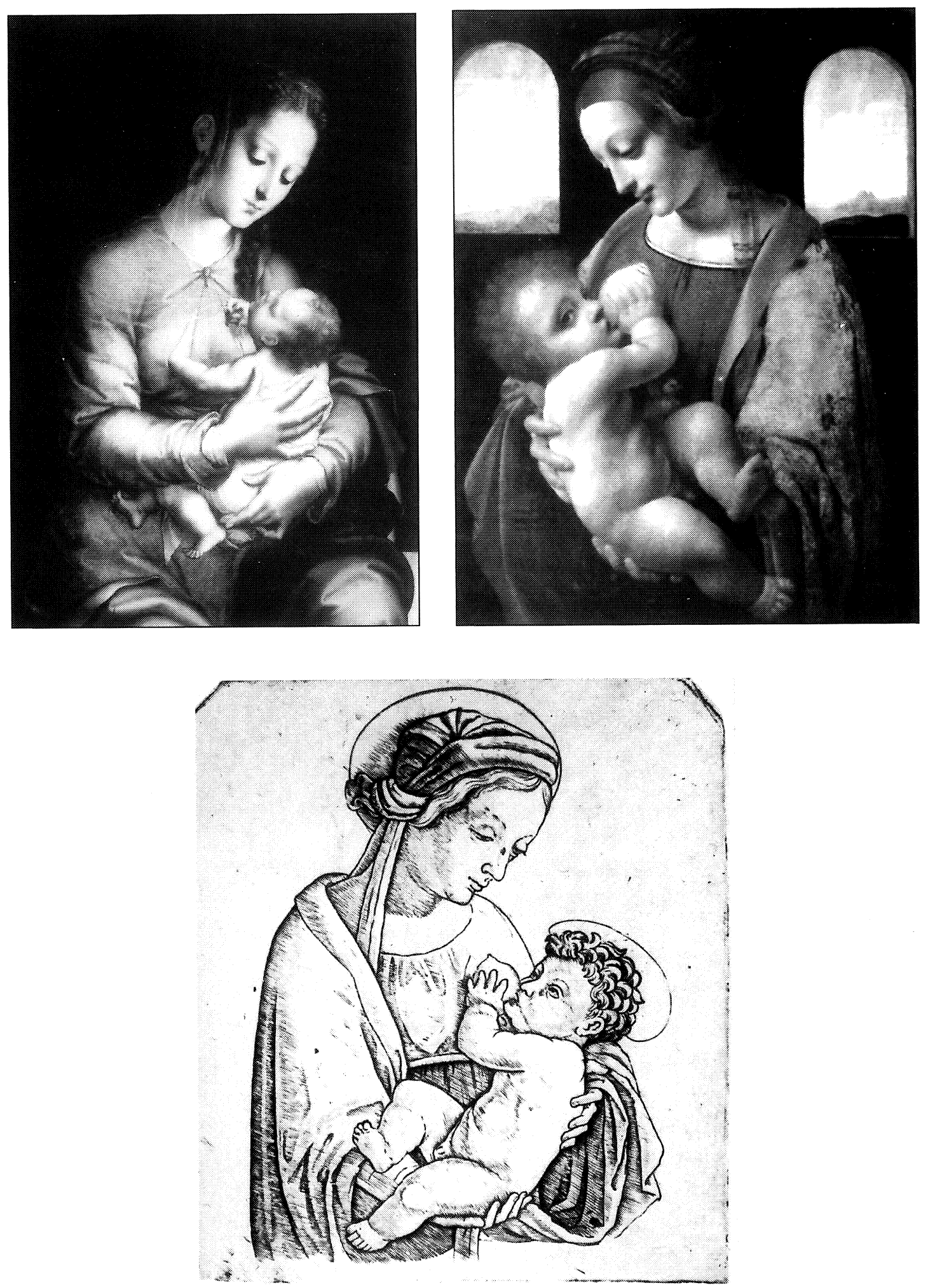

Fig. 1. Luis de Morales, La Virgen y el Niño («La Virgen de la Leche»). Madrid, Museo del Prado.

Fig. 2. Leonardo da Vinci, La Virgen con el Niño («Madonna Litta»). San Petersburgo, Museo del Ermitage.

Fig. 3. Zoan Andrea, La Virgen con el Niño. Grabado. 
Un representante típico del manierismo español es Luis de Morales. Su formación artística tuvo lugar en la época del concilio de Trento y su madurez y periodo tardío coinciden con la Contrarreforma. Un influjo fundamental en la configuración de su lenguaje artístico lo ejerció la obra de Leonardo. El sutilísimo modelado del claroscuro de las formas de Morales procede del «sfumato» leonardesco. Morales usó también las composiciones del maestro de Vinci y de su círculo. Camón Aznar, parafraseando a A. Palomino, llamó a Morales «Leonardo a lo divino» ${ }^{10}$.

E. Du Gue Trapie ha señalado que para el cuadro «La Virgen de la rueca» Morales se ha servido del tema del cuadro de Leonardo, ahora perdido, «Madonna del huso» ${ }^{11}$. Según su opinión, muy probablemente la fuente de inspiración para el tema del cuadro «La Virgen con el Niño y San Juanito» ha sido la obra de Bernardino Luini «La Sagrada familia», que en el siglo XVI se consideraba indudablemente obra de Leonardo ${ }^{12}$. La investigadora norteamericana señalaba en este sentido la relación entre el cuadro de Morales «El Ecce Homo» de la Hispanic Society of America y la composición del Giampetrino sobre ese mismo tema de la Galleria Ambrosiana de Milán ${ }^{13}$.

Hasta el momento presente sigue abierta la cuestión de dónde pudo el maestro extremeño conocer las obras originales italianas. Entre la fecha probable del nacimiento del artista (1519/ 20) y la primera obra firmada por él que es posible datar (1546) median 26 años, lo cual es un lapso de tiempo considerable. La ausencia de materiales de archivo ha provocado hipótesis y leyendas de diverso tipo acerca de la formación artística del maestro. Trapie suponía que Morales conoció la escuela lombarda en torno al 1574, durante su estancia en Madrid, estudiando la colección de pintura que se encontraba en el Escorial ${ }^{14}$. Sin embargo los influjos leonardescos aparecen en la obra de Morales mucho antes de que emprendiese el camino de Castilla, a la corte de Felipe II. El investigador español J.A.Gaya Nuño ha avanzado la hipótesis de un viaje de Morales a la península itálica a finales de los años 30 o los primeros años de los 40 del siglo XVI ${ }^{15}$. Sin embargo no existe ningún testimonio documental de un viaje del pintor extremeño a Italia. Morales pudo conocer algunos prototipos italianos en Sevilla, donde, como mostró A. Palomino, trabajó en el taller del pintor flamenco Pedro de Campaña, que había pasado un tiempo notable en Italia ${ }^{16}$. Elías Tormo cree que Morales pudo ver obras de la escuela lombarda en Evora, importante centro cultural portugués, donde estuvo en los años 1540 y $1560{ }^{17}$. Se ha manifestado incluso la suposición de que el pintor habría recibido el influjo italiano, y particularmente de Leonardo, preferentemente gracias a los grabados. Sin embargo, de la composición de Leonardo da Vinci no existe una gran cantidad de grabados en comparación con otros autores y además de esto, en el grabado prácticamente es imposible lograr el «sfumato», que constituye precisamente la particularidad del pintor extremeño. Lo más probable es que Morales haya podido conocer composiciones de Leonardo, sea gracias a algunos grabados, o los cuadros de sus discípulos que existían en la Península Ibérica, así como a las copias del siglo XVI realizadas por pintores españoles y flamencos. Queremos dirigir nuestra atención a algunas fuentes iconográficas nuevas de la obra de Morales relacionadas con el circulo de Leonardo da Vinci que hasta el momento actual no habían sido tenidas en cuenta por los investigadores.

\footnotetext{
${ }^{10}$ Luis de Morales era llamado «El Divino» por cuanto su producción tenía carácter exclusivamente religioso. Véase: Palomino de Castro, A., El Museo pictórico y escala óptica. Madrid, 1795, tomo 3, p. 384; Camón Aznar, J., La pintura española del siglo Xvi. Summa Artis. Historia general del arte. Madrid, 1970, vol. 24, p. 461.

${ }^{11}$ Trapie Du Gue, E.: Op. cit., pp. 28, 29, fig. 17.

12 Trapie Du Gue, E.: Op. cit., pp. 21, 22, fig. 12.

${ }^{13}$ Ibid., p. 32, fig. 20.

${ }^{14}$ Ibid., pp. 21, 22.

${ }^{15}$ Gaya Nuño, J.A., Luis de Morales. Madrid, 1961, pp. 9-11.

${ }^{16}$ Palomino de Castro, A., Op. cit., tomo 3, p. 384.

AEA, LXXVII, 2004, 308, pp. 411 a 438
} 

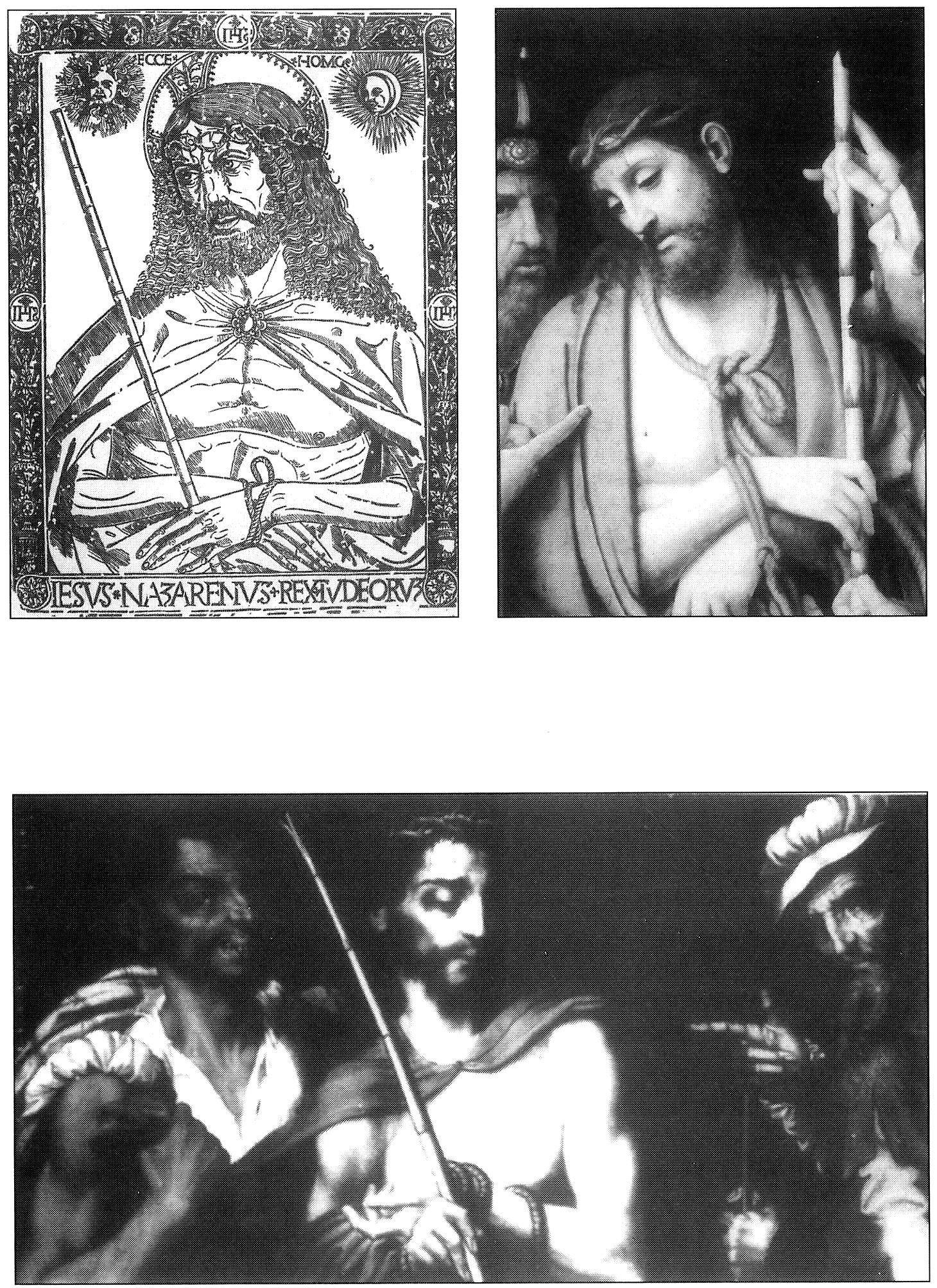

Fig. 4. Maestro lombardo anónimo de finales del siglo xv. Ecce Homo. Grabado en madera. Hamburgo. Kunsthalle.

Fig. 5. Andrea Solario, Ecce Homo. Oxford, Museo Ashmolean.

Fig. 6. Luis de Morales, Ecce Homo («Cristo ante Pilatos»). Madrid, Museo de la Real Academia de Bellas Artes de San Fernando. 
Al número de imágenes «arquetípicas» en el arte de Morales pertenece su obra «La Virgen y el Niño», o más conocida como «La Virgen de la Leche» (Fig. 1), de la cual existen diversas versiones, la más famosa de las cuales es la que se guarda en el Museo del Prado. Creemos que el tema de esta obra tiene su origen en el cuadro «La Virgen y el Niño» (Fig. 2) de Leonardo da Vinci que se encuentra en el Museo del Ermitage y que procede de la colección Litta de Milán. La composición de Leonardo era ampliamente conocida a través de un sinnúmero de réplicas y reproducciones. M. A. Gukovskij en el libro consagrado al cuadro de la Madonna Litta, presenta una serie de obras, cuyo modelo de inspiración tiene que haber sido precisamente el cuadro del Ermitage ${ }^{18}$. No existen indicios manifiestos de la presencia de copias de la Madonna Litta en la Península Ibérica ${ }^{19}$. Sin embargo, J. M. Ruiz Manero en su investigación dedicada a Leonardo y los leonardescos en España, indica que en los antiguos inventarios de los siglos XVI y XVII se encuentra la noticia de cuadros con la imagen de la Virgen con el Niño debida al pincel de Leonardo da Vinci, si bien por lo lacónico de la descripción no es posible determinar de qué imagen de la Virgen se trata, si se habla de trabajos originales del maestro italiano o de copias de artistas de su escuela. Además, en las colecciones de la nobleza española existían obras de Cesare da Sesto y Andrea Solario sobre el tema de la Virgen de la Leche ${ }^{20}$. Es posible que Morales se relacionase con una imagen de este tipo por exigencia de uno de los comitentes nobles que tenía una copia o una réplica de dicho cuadro. En el patrimonio artístico del supuesto maestro de Morales, Pedro de Campaña, estaba el cuadro «La Virgen de la Leche» ${ }^{21}$. Es sabido que Campaña, por comisión del cardenal Grimani estuvo en Venecia, donde pudo ver la referida composición de Leonardo, que se encontraba por aquel entonces en el palacio de Pietro Contarini ${ }^{22}$, e incluso pudo realizar una copia pictórica de la misma. Campaña estaba estrechamente relacionado con el duque de Alcalá, riquísimo virrey de Nápoles, a quien llamaban «el Médicis sevillano». En un antiguo inventario, entre las obras de arte que el duque poseía en su palacio, la llamada «casa de Pilatos», se mencionaba el retrato de un clérigo debido al pincel de Leonardo da Vinci ${ }^{23}$. Es posible que en dicha colección hubiese otros cuadros relacionados con el nombre de Leonardo. La investigadora finlandesa $\mathrm{J}$. Backsbacka opinaba que Morales realizó una de las versiones de la Virgen con el niño, por encargo del hijo del duque de Alcalá, el obispo de Badajoz, Juan de Ribera ${ }^{24}$.

El pintor aragonés Jusepe Martínez en el tratado «Discursos practicables del nobilísimo arte de la pintura» escrito en 1675, habla de un grabado de Leonardo con la imagen de la Virgen amamantando al Niño ${ }^{25}$. Una estampa con este tema estaba en poder del marqués de Lierta y Ayerbe en el siglo XVIII ${ }^{26}$. En ambos casos se trataba probablemente de un grabado bastante

\footnotetext{
${ }^{17}$ Ambel Albarrán, M.; Araya Iglesias, C.; Blanco Nieto, G.; Grau Lobato, G., Luis de Morales y su tiempo. Junta de Extremadura, 2000, p. 34 .

${ }^{18}$ Gukovskij, M.A., Madonna Litta, L.-M., 1959, pp. 69-79, fig. 30-41.

${ }^{19}$ En el Museo del Prado se guarda un cuadro, pintado por un artista desconocido, español o flamenco del siglo xvi que representa a la Virgen María amamantando a su Hijo. Su composición apunta a la obra del Ermitage. Véase: Museo del Prado. Inventario general de Pinturas. El Museo de la Trinidad. (Bienes desamortizados), tomo II. Madrid, 1991, p. 267, cat. n. ${ }^{\circ}$ 875. Es posible que la pintura «Virgen de la Leche» referida a Joan de Joanes (Valencia, colección particular) se relacionase con este tipo de composición. Véase: Benito Domenéch, F., Una nueva visión del artista y su obra, Valencia, 2000, catálogo, p. 209.

${ }^{20}$ Ruiz Manero, J.M.: Op. cit., pp. 101, 106.

${ }^{21}$ Camón Aznar, J.: Op. cit., p. 401, fig. 358.

${ }^{22}$ Gukovskij, M.A.: Op. cit., pp. 49-50, 84.

${ }^{23}$ Ruiz Manero, J.M.: Op. cit., p. 10.

${ }^{24}$ Backsbacka, J.: Op. cit., pp. 96, 219.

${ }^{25}$ Trapie Du Gue, E.: Op. cit., p. 39.

${ }^{26}$ "Grabado con una imagen de Madonna amamantando al Niño a partir de un original de Leonardo da Vinci» - Martínez, J., Edic. Carderera. 1866. Apéndice IV, p. 215 (A). «Es posible que se trate de una copia de la Madonna Litta, atribuida por algunos críticos a Leonardo». Cfr.: Ruiz Manero, J.M.: Op. cit., p. 45.
}

$A E A$, LXXVII, 2004, 308, pp. 411 a 438 
raro del maestro milanés Zoan Andrea (Fig. 3), ejecutado, según parece a partir de un dibujo que Leonardo habría realizado como preparación para la Madonna Litta ${ }^{27}$. Morales pudo conocer este grabado y retomar la idea general de Leonardo.

Llama la atención la cercanía de los esquemas compositivos del grabado y del cuadro de Morales. Es claramente visible el origen leonardesco de los tipos de la Virgen y el niño Jesús. Además el rostro de la Virgen es asombrosamente parecido a un boceto pictórico atribuido a Leonardo llamado «cabeza de mujer joven» («La Scapiliata») que se encuentra en la Galería Nacional de Parma ${ }^{28}$.

Simultáneamente, el original leonardesco ha sido sometido en la composición del artista español a una notable transformación. Las figuras están representadas sobre un impenetrable fondo oscuro. La Virgen María, sentada y representada hasta las rodillas, está más vuelta hacia el espectador. Ha cambiado la posición de las manos de la Virgen, su tocado sobre la cabeza, así como la posición y los gestos del Niño ${ }^{29}$. El pintor no ha mostrado el pecho desnudo de María y ha envuelto al Niño en un tejido blanco, debido a que en aquel tiempo, después del concilio de Trento estaba terminantemente prohibido en el arte religioso la representación del cuerpo desnudo. Morales conscientemente rompe las proporciones naturales de las figuras, alarga y hasta deforma un poco los miembros del cuerpo, gracias a lo cual adquieren una especial fragilidad. En cuanto al colorido, el cuadro del pintor español también se distingue notablemente de la obra de Leonardo, que está pintada a la témpera.

Pero sobre todo los cuadros se distinguen entre sí debido a una profunda diferencia espiritual de fondo. Leonardo para su composición ha usado el canon de belleza de la antigüedad clásica, muy extendido en la Florencia de su tiempo, que acentúa los sentimientos naturales que vinculan a madre e hijo. La composición de Morales reproduce un tipo iconográfico parecido, pero en ella se percibe mucho más fuertemente su relación con el icono, con la simbología religiosa. Si en el cuadro del pintor italiano la contemplación del Niño despierta en el rostro de la Madre una sonrisa apenas perceptible, la Virgen del maestro español se halla concentrada interiormente y sumida en el doloroso presentimiento de la futura Pasión del Hijo. J.A. Gaya Nuño ha hecho notar la ausencia de sonrisa en los rostros de las Vírgenes pintadas por Morales, incluso en las más jóvenes ${ }^{30}$. En los tratados religiosos españoles frecuentemente se colocaba a la Virgen amamantando al Niño, junto a las representaciones de la Virgen con el Hijo muerto en sus rodillas, la llamada «quinta angustia» (en la tradición iconográfica ortodoxa «Oplakivaniye» o llanto por el Hijo muerto). La imagen de Morales, cargada de expresividad y dramatismo místico y religioso cuadra perfectamente con la atmósfera cultural e ideológica de la época de la Contrarreforma.

Un puesto central en la obra de Morales lo ocupa el tema del «Ecce Homo». Por aquel tiempo crece especialmente la relevancia de este tema pictórico. Los autores religiosos contemporáneos del pintor, como Ignacio de Loyola, Juan de Ávila o Luis de Granada insistían en la devoción a Cristo, especialmente al Cristo sufriente, al Cristo encarnado e histórico que derramó su sangre en la cruz por nuestra salvación.

\footnotetext{
${ }^{27}$ Vease: The Illustrated Bartch. Early Italian masters. V. 25. New York. 1980, p. 148. El grabado de Zoan Andrea se encuentra también en el artículo: Marani, C.: «Una «Madonna Litta» tedesca», Achademia Leonardi Vinci. Journal of Leonardo Studies \& Bibliography of Vinciana., vol. IV, Firenze. Italy, 1992, pp. 200-202.

${ }^{28}$ Gukovskij, M.A., Op. cit., pp. 10,43; Kustodieva, T.K., Proisvedeniya shkoly Leonardo da Vinci v sobranii Ermitaga. Kamalog vystavki. San Petersburgo, 1998, pp. 178-179.

${ }^{29} \mathrm{El}$ gesto de la mano derecha de Jesús es parecido a los gestos de los niños de los cuadros de A. Solario «Madonna de la Leche» (Milán, Museo Poldi Pezzoli), «Virgen y el Niño» de Cesare da Sesto (Milán. Pinacoteca Brera), «La Virgen del clavel» de Leonardo. Es sabido que en España en el siglo xvi existían copias de la Virgen del clavel, así como también de los cuadros arriba referidos de A. Solario y C. Da Sesto sobre el tema de la Virgen de la leche o bien copias de los mismos. Vease: Gukovskij, M.A.: Op. cit., p. 77, fig. 33; Ruiz Manero, J.M.: Op. cit., p. 7.

${ }^{30}$ Gaya Nuño, J.A.: Op. cit., pp. 17-19.
} 
En el transcurso de los años 1550 a 1570, Morales dirigió su atención en reiteradas ocasiones al tema del Ecce Homo. Sus composiciones representaban una imagen no muy grande de Cristo, coronado de espinas o con llagas en la frente, con el cordel al cuello, con el manto y el cetro de caña en sus manos y proyectadas con relieve casi escultórico sobre un fondo neutro ${ }^{31}$. Las últimas generaciones se admiraban de estas representaciones de Morales viendo en tales imágenes ascéticas, realizadas con la típica expresividad española, la encarnación de la religiosidad apasionada y fanática y del misticismo, reflejo del carácter nacional.

La iconografía de tales cuadros está estrechamente relacionada con el modo de tratar dicho tema por parte de la escuela lombarda. Una de sus más tempranas versiones, la que representa a Cristo de medio cuerpo y coronado de espinas sobre fondo negro, en conformidad con la palabras del evangelio de Juan $(19,4-6)$, se halla vinculada al círculo milanés de Leonardo da Vinci ${ }^{32}$. Un grabado en madera de un maestro lombardo anónimo de finales del siglo XV reproduce este mismo tipo de iconografía (Fig. 4), representando a Cristo algo esquemática y rudamente. En la parte superior de la imagen está escrito: «ECCE HOMO» y en la parte inferior «IESVS NAZARENVS REX IVDEORVM». E. Panofsky llamaba a este arquetipo «fórmula milanesa». Este tipo compositivo ejerció un enorme influjo en la pintura aquende y allende los Alpes y se utilizaba no sólo en las composiciones en que Jesús es representado solo, sino incluso en otras, donde «se convirtió en el núcleo de un nuevo tipo de imágenes compuestas de tres figuras, donde Cristo está representado de medio cuerpo entre Pilatos y un soldado» ${ }^{33}$.

Creemos que por su similitud las obras de Morales sobre este tema están más vinculadas a las obras del artista milanés Andrea Solario, uno de los representantes de la escuela de Leonardo con más talento ${ }^{34}$. B. Bergson ha comparado el conocido trabajo de Solario de la colección John Jonson en el museo de Filadelfia con la obra de Morales por su expresividad emocional ${ }^{35}$. Sin embargo hasta el momento presente no conocemos ninguna indicación en la literatura especializada acerca de la obra de Solario como fuente iconográfica inspiradora de Morales.

Según nuestra opinión, es probable que el cuadro de Solario «Ecce Homo» (1505-1507, Oxford, Museo Ashmolean) (Fig. 5) que representa a Cristo entre Pilatos y un soldado, o una reproducción de dicho cuadro, haya sido la fuente iconográfica del famoso cuadro de Morales sobre este mismo tema que se encuentra en la Academia de San Fernando de Madrid ${ }^{36}$ (Fig. 6).

\footnotetext{
${ }^{31}$ Rodríguez G. de Ceballos, A., «El mundo espiritual del pintor Luis de Morales en el IV centenario de su muerte», Goya, 1987, n. ${ }^{\circ} 196$, p. 198.

${ }^{32}$ Como es sabido, la iconografía del «Ecce Homo» (Jn. 19, 4-6) recibe en el arte occidental europeo un tratamiento que da origen a dos tipos diversos fundamentales. El primero de ellos es una composición narrativa de muchas figuras, que representa la presentación de Cristo por Pilatos al pueblo de Jerusalén. Para dicho tipo E. Panofsky ha acuñado el término tardo-medieval de «Ostentatio Christi». El segundo es una imagen que despierta la devoción, es decir «imago devotionis», y representa al Salvador coronado de espinas, de medio cuerpo y con fondo negro. Véase: Panofsky, E., «Jean Hey’s "Ecce Homo", speculations about its Autor, its Donor and its Iconography”, Bulletin des Musées Royaux des Beaux-Arts, n. ${ }^{\circ} 3-4$, 1956 , p. 102. Morales representaba el tema del Ecce Homo en los cuadros de una sola figura o en los trípticos de pequeño formato con «pocas figuras de escasa acción, más volcadas hacia su mundo interior que hacia la actividad externa y donde, pese a la minuciosidad y casi miniaturística anotación de pormenores de raíz flamenca, nunca se pierde la atención a lo esencial». A. Rodríguez G. de Ceballos: Op. cit., p. 198.

${ }^{33}$ Panofsky, E.: Op. cit., pp. 115-116.

${ }^{34}$ Las composiciones de Andrea Solario representan uno de los ejemplos más primigenios de la aparición de dicha iconografía en el norte de Italia. Por primera vez el artista se ocupa de este tema en un cuadro que se encuentra hoy en día en Milán en el Museo Poldi Pezzoli. Más tarde incluyó en el tratamiento de este tema algunos cambios que unen la «fórmula milanesa con la iconografía que se remonta a las imágenes de A. Mantegna y A. da Messina.

${ }^{35}$ Berenson, B., Catalogue of a collection of paintings and some art objects. Italian paintings by Bernard Berenson. Philadelphia, 1913, vol. I, p. 177, cat. N. ${ }^{\circ}$ 274; Brown D.A., Andrea Solario. Milano, 1987, p. 138, N. $^{\circ} 140$.

${ }^{36}$ El Ecce Homo de la Hispanic Society of America es el primero de una serie de composiciones que se repetirán en los retablos de las iglesias parroquiales de Higuera la Real y Arroyo de la Luz, en los cuales las figuras están representadas enteras. La mejor obra de esta serie es el Ecce Homo de la Academia de San Fernando de Madrid ejecutado en torno a 1570, en el cual Cristo está representado entre Pilatos y un sayón. Véase: Trapie Du Gue, E.: Op. cit., p. 32.
}

AEA, LXXVII, 2004, 308, pp. 411 a 438 
Una composición de tres figuras que da la posibilidad de contraponer el bien y el mal a través de imágenes de perfectos y de deformes era muy popular en el círculo de Leonardo ${ }^{37}$. El tipo de Cristo pintado por Morales es muy cercano al tipo pintado por Solario, sin embargo el maestro español acentúa su expresividad: arquea las cejas, cargadas de dolor, acentúa las cuencas de los ojos, semirrecubiertas de pesados párpados, oscurece las mejillas hundidas en el demacrado rostro de Jesús, alarga fuertemente las proporciones de su figura, consiguiendo de este modo transmitir la profundidad de los sufrimientos, físicos y anímicos, del Salvador. La alteración de las proporciones naturales de la figura y su deformación recuerdan las formas del arte medieval.

En la pintura italiana la representación de Cristo se realiza con arreglo a la comprensión de la perfección propia del Renacimiento. La imagen realizada por Morales transmite un ideal de ascetismo religioso que corresponde a la mentalidad de la época posterior al concilio de Trento. A. Rodríguez G. de Ceballos ha señalado que Morales «acertó como nadie -á excepción acaso del Greco - a expresar la crispada religiosidad y el agudizado espiritualismo de la sociedad española de la segunda mitad del siglo XVI...» ${ }^{38}$. Sus figuras misteriosamente difuminadas por el «sfumato» leonardesco «se demacran y languidecen como si estuvieran vistas desde un concepto religioso, basado primordialmente en el maceramiento ascético y en la dolorosa renuncia a todo lo sensual y placentero... ${ }^{39}$.

Sin embargo, los tipos de Pilato en los cuadros de Morales y Solario son extraordinariamente cercanos. Sus rostros están representados en ángulo de tres cuartos, las figuras en escorzo, recortadas según el límite vertical del marco. En ambos hay los mismos gestos indicativos en la mano derecha. Las mismas imágenes casi caricaturescas de las cabezas de los que martirizan a Cristo en la parte derecha, parecidas a los dibujos de cabezas grotescas de Leonardo. Entre las obras de Morales frecuentemente se puede ver el cuadro del «Ecce Homo» compuesto por una sola figura. «Es cuando el pintor prescinde de toda connotación espacial y temporal, como si la imagen fuera una imagen mental más que real y la acción transcurriera fuera del tiempo...» ${ }^{40}$. En estos cuadros el maestro español no siempre ha representado la corona de espinas y ha cambiado una serie de detalles, lo que le valió la crítica de F. Pacheco, que acusó al pintor de desdén con relación a la iconografía religiosa ${ }^{41}$. Estos cuadros a veces se completan con otros cuadros paralelos con representaciones de los dolores de María. «Estas escenas quintaesenciadas de la pasión de Cristo y de los dolores de su Madre eran, efectivamente, las elegidas por aquel público enfervorizado...» ${ }^{42}$. Como ejemplo se puede traer el díptico realizado en los primeros años de la década de 1570 (Málaga, Museo de Bellas Artes). J. Backsbacka ha señalado que perteneció a Felipe III y en el año 1614 fue trasladado a la capilla del palacio del Pardo, cerca de Madrid. La investigadora finesa suponía que Morales o bien recibió este encargo del palacio real, o bien que algún alto cargo eclesiástico de Extremadura lo envió como regalo a Madrid ${ }^{43}$. Como base de este trabajo pudo usar algunos altares portátiles de doble hoja de tipo flamenco de finales del siglo xv pertenecientes al círculo de Dirk Bouts ${ }^{44}$. Sin embargo, la iconografía de los tipos de Morales, no sólo de Cristo, sino también de su Madre, tiene un origen italiano muy concreto o procede de los prototipos flamencos italianizados del siglo xvi en España.

\footnotetext{
${ }^{37}$ Se puede, por ejemplo, comprobar en el cuadro de Bernardino Lanino, «Ecce Homo» (San Silano, Romagnano Sesia). Vease: Kwakkelstein, T.W., «The Lost Back on "moti mentali"», Achademia Leonardi Vinci. Journal of Leonardo Studies \& Bibliography of Vinciana, vol. VI, Firenze, Italy, 1993, p. 66.

${ }^{38}$ Rodríguez G. de Ceballos, A.: Op. cit., p. 194.

${ }^{39}$ Ibidem.

${ }^{40}$ Ibidem, p. 198

${ }^{41}$ Trapie Du Gue, E.: Op. cit., p. 32.

${ }^{42}$ Rodríguez G. de Ceballos, A.: Op. cit., p. 198.

${ }^{43}$ Backsbacka, J.: Op. cit., p. 115.

${ }^{44}$ Panofsky, E.: Op. cit., pp. 112, 118, fig. 22, 29.
} 
En el Museo del Ermitage de San Petersburgo se conserva un díptico que representa a Cristo coronado de espinas y a la Madre Dolorosa realizado por uno de los maestros del círculo de Solario ${ }^{45}$. Este díptico se remonta a un díptico no conservado del maestro milanés ${ }^{46}$. En la colección de la Galería Borghese de Roma se encuentra otra copia de este altar portátil de doble puerta realizada por Simón de Chalonom en el año $1534^{47}$. Estas copias testifican la popularidad de este tipo de imágenes. La representación de Cristo es una copia clara de las composiciones del «Ecce Homo» firmadas por Andrea Solario de los museos de Leipzig y Filadelfia, pero tiene un mayor corte de la figura. La Madre Dolorosa del Ermitage también repite un trabajo similar de Solario procedente de la colección Crespi de Milán y que hoy se conserva en un museo privado en Zurich ${ }^{48}$.

En el díptico de Morales arriba mencionado, la imagen de la Virgen María es extraordinariamente parecida a las imágenes de este tipo de los cuadros del pintor italiano. La figura de medio cuerpo de María está representada sobre fondo negro en idéntico escorzo de tres cuartos que encontramos en el pintor italiano. El tipo de Madonna es el mismo, si bien en Morales es más joven, y es también idéntico el ropaje. Es cierto que la posición de sus manos es diversa, y el ritmo de los pliegues en el cuadro del maestro español es más complejo y duro.

Una réplica más tardía de la Madre Dolorosa, realizada por Morales a mitad de la década de 1570, se encuentra en el museo del Ermitage. Las diferencias entre ambas no son sustanciales y proporcionalmente resultan mucho más preponderantes las coincidencias de matices colorísticos y algunos detalles significativos. Por ejemplo, los dedos de la Virgen Santa del cuadro del Ermitage son más largos, nudosos, y Morales los ha pintado con un sentimiento religioso tan apasionado, que traen a la memoria las palabras del poeta andaluz B. Acosta Quintana de que parece como si en ellos se concentrara todo el dolor de la Madre producido por los sufrimientos de su Hijo en la cruz ${ }^{49}$.

Es probable que este cuadro formase parte de un díptico, si bien en el momento presente no es conocido ningún trabajo de Luis de Morales sobre el tema del Ecce Homo que coincida por tamaño y características de estilo con el cuadro de la Madre Dolorosa del Ermitage.

Creemos que las obras mostradas de la escuela lombarda permiten ensanchar el círculo de las fuentes iconográficas de los trabajos pictóricos de Morales.

Elena O. Kaluguina Museo Tsarkoye Selo, San Petersburgo

\section{DOS RÉPLICAS INÉDITAS DEL TALLER DE MURILLO EN EL PALACIO ARZOBISPAL DE TOLEDO}

Si la fama de Murillo contribuyó a hacer descubrir la maestría de la pintura española, favoreciendo la dispersión masiva de su obra fuera de España, al ser representada hoy día en museos del mundo entero, el palacio arzobispal de Toledo conserva sin embargo dos réplicas

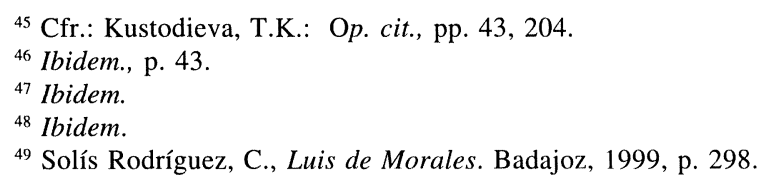

